\title{
Spondyloepimetaphyseal dysplasia, Bieganski type
}

INSERM

\section{Source}

INSERM. (1999). Orphanet: an online rare disease and orphan drug data base. Spondyloepimetaphyseal dysplasia, Bieganski type. ORPHA:168448

Spondyloepimetaphyseal dysplasia, Bieganski type is a rare primary bone dysplasia disorder characterized by infantile-onset, progressive, multiple skeletal deformities in association with slowly progressive central and peripheral neurodeg eneration. Patients present short stature, coarse facies, psychomotor regression and cog nitive impairment. Imaging shows abnormally-shaped vertebral bodies, small, flat epiphyses, and widened metaphyses, as well as cerebral and cerebellar atrophy and progressive axonalhypomyelinating neuropathy. 